\title{
Can the Tinnitus Magnitude Index Reflect the Depression and Anxiety of Tinnitus Sufferers?
}

\author{
Ha Ryun Kim ${ }^{1,2}$, Junghwa Bahng ${ }^{1,3}$ \\ ${ }^{1}$ Department of Audiology and Speech Language Pathology, Hallym University of Graduate Studies, Seoul, Korea \\ ${ }^{2}$ Hear \& Say Center, Myeong ENT Clinic, Cheonan, Korea \\ ${ }^{3}$ HUGS Center for Hearing and Speech Research, Seoul, Korea
}

Received: May 17, 2021

Revised: September 3, 2021

Accepted: September 3, 2021

Correspondence:

Junghwa Bahng, PhD

Department of Audiology and

Speech Language Pathology, Hallym

University of Graduate Studies, 427

Yeoksam-ro, Gangnam-gu, Seoul

06197, Korea

Tel: $+82-70-8638-6833$

Fax: $+82-2-3453-6618$

E-mail: bahng.jh@hallym.ac.kr

\begin{abstract}
Purpose: This study evaluates the relationship between tinnitus magnitude and depression and statetrait anxiety. Methods: A total of 65 subjects suffering from tinnitus participated. None reported any hearing problems. The participants filled in the Tinnitus Magnitude Index (TMI), the Korean version of the Beck depression inventory, and the Korean version of state-trait anxiety questionnaires with 61 out of 65 subjects completing all the questionnaires. Results: No significant relationships between tinnitus magnitude and depression or state-trait anxiety were found. However, items for the TMI were found to be significantly related $(p<0.05)$, and depression and state-strait anxiety also had a significant relationship $(p<0.05)$. Conclusion: We concluded that the TMI was not sensitive when used for assessing depression and anxiety in individuals who are suffering from tinnitus, which implying that the TMI questionnaire is useful for a quick assessment tool of the severity of tinnitus in individuals.
\end{abstract}

Key Words: Tinnitus, Tinnitus Magnitude Index, Depression, Anxiety.

\section{INTRODUCTION}

이명은 외부의 소리가 존재하지 않지만 귀에서는 소리가 들리 는 것 같은 느낌을 갖는 증상을 의미한다. 이명의 양상은 매우 다양하다. 이명의 소리는 “삐 ", “윙 ", 귀뚜라미 소리, 파도 소 리, 폭포수 소리 등 다양하게 나타나며 소리가 들리는 측은 일 측에서도 발생하기도 하지만 양측에서 발생하기도 하며 머리 안 쪽 어디에서 들리는지 구분을 하지 못하기도 하다. 사람에 따 라 이명이 간헐적으로 들리기도 하지만 지속적으로 들리기도 한 다(Bahng \& Lee, 2020; Han et al., 2009). Dauman and Tyler(1992)에 따르면 병리학적으로 문제가 되는 이명의 경우 최소 일주일에 한 번씩 5분 이상 지속되면서 발생한다고 하였다.

미국이명협회(American Tinnitus Association [ATA]; ATA, 2019)에서는 미국 인구의 약 $15 \%$ 가 이명 증상을 경험하 였고 약 20만 명의 사람들이 만성적인 이명을 겪고 있으며 이 중 2만 명의 사람들은 이명으로 인하여 극도의 어려움을 겪는다고

(c) This is an Open Access article distributed under the terms of the Creative Commons Attribution Non-Commercial License (https://creativecommons.org/ licenses/by-nc/4.0) which permits unrestricted non-commercial use, distribution, and reproduction in any medium, provided the original work is properly cited.
보고하였다. 2009년부터 2012년까지의 국민건강영양조사의 결 과를 분석한 결과 우리나라 인구의 약 $20.7 \%$ 가 이명이 있다고 보고하였다(Kim et al., 2015). 국외의 이명 유병률에 관한 연구 에 따르면 우리나라와 비슷한 비율의 인구가 이명을 겪고 있는 것으로 나타났다(Michikawa et al., 2010; Oiticica \& Bittar, 2015).

이명은 이명 자체의 문제도 있지만 이명으로 인하여 여러 정신 적인 문제와 관련이 되기 때문에 심각성이 더해진다. Kraus and Canlon(2012)은 외부의 자극이 없는 소리가 뇌에서 들리는 경 험은 뇌의 청각적 영역에만 영향을 끼치는 것이 아니라 대뇌변연 계(limbic system)에도 경험을 축적하게 된다. 대뇌변연계의 편 도체(amygdala)와 해마(hippocampus)는 이러한 기억에 관여 를 하게 된다. 특히, 편도체의 경우 소리의 의미를 부여하는 역할 을 하게 된다. 이명이 들릴 때마다 사람들은 "내 귀에 병이 있는 건 아닐까?", “나는 곧 귀가 안 들리게 되는 것은 아닐까?”하는 불안, 초조, 화, 우울 등의 부정적 감정을 기억하고 이후 이명이 들릴 때 마다 자동적인 감정적 반응을 보이게 된다. 이로 인하여 이명이 있는 사람들은 사회적 활동에서 흥미와 즐거움을 제대로 느끼지 못한다(Moring et al., 2016). 이명이 없는 사람의 우울 
증의 비율은 $9 \%$ 인데 반해, 이명이 있는 사람의 경우 $25.6 \%$ 의 비 율을 보이며, 불안증은 각각 $9 \%$ 와 $26.1 \%$ 의 비율을 보여 이명이 있는 사람들에게 정신적인 문제에 대한 적절한 중재가 필요한 것 으로 나타났다(Makar et al., 2014).

이명이 개인에게 어떻게 들리는가를 음향학으로 측정할 수 있 는 방법으로는 이명도(tinnitogram)검사가 있다. 그러나 이명 도검사만으로는 이명이 심리적, 정서적으로 끼치는 영향에 대하 여 알 수 없다. 이명으로 인한 삶의 질의 전반적인 영향을 측정하 기 위해서 여러 이명관련 설문지를 실시한다(Lee et al., 2018). 현재 이명에 관한 실문지는 많은 종류가 개발되어있고 목적에 따 라 문항의 요소가 다양하게 구성되어 있다. 다양한 이명 설문지 중 Lee et al.(2018)의 연구에서는 임상에서 많이 쓰고 있는 설 문지 Tinnitus Handicap Questionnaire (THQ), Tinnitus Handicap Index, Tinnitus Functional Index (TFI) 그리고 Tinnitus Parimary Functional Questionnaire를 분석하였 다. 분석 결과 각각의 설문지는 조금씩 특징은 다르지만 우울, 화 등의 감정적인 부분에 대한 문항을 공통적 하위영역으로 포함 하고 있다. 이 외 집중의 문제, 삶의 전반적인 질 문제 등을 알 수 있는 항목이 포함되어 있어 이명으로 인한 심리적, 정신적 문제 등을 파악할 수 있도록 되어있다. 그러나 이 설문지는 모두 20 문 항 이상으로 구성되어 있어 답변을 하는데 시간이 많이 소요되 고 이해하기 어려운 문항 등이 있는 단점이 있다. 이러한 문제로 바쁜 임상에서 긴 설문지의 작성은 어려울 수 있다. 그리고 이명 으로 인한 어려움을 파악하기 위한 설문은 이명을 겪고 있는 사 람에게는 설문을 하는 동안 오히려 이명에 대한 스트레스가 발 생할 수 있다(Hwang \& Bahng, 2018).

앞에 제시한 기존 설문지의 어려움을 보완하여 Schmidt et al.(2014)은 이명의 규모(magnitude)를 묻는 3문항으로 이루 어진 설문지 이명규모지수(Tinnitus Magnitude Index, TMI) 를 개발하였다. 여기서 이명의 규모는 주관적으로 이명을 지각 하는 크기이다. TMI 문항은 한 주 동안의 이명의 크기, 인지하는 시간 그리고 대상자가 느끼는 심각성을 연속척도로 답하게 되어 있다. 개발자 Schmidts et al.(2014)은 이명의 주관적 규모는 이 명에 대한 인지 및 행동 그리고 주변 환경요소에 대하여 변할 수 있어 본인이 느끼는 이명의 규모를 측정하게 되면 이명에 대한 여 러 반응을 알 수 있을 것이라 하였다. 예를 들어 이명의 규모는 주관적인 이명의 크기로 이명의 규모가 작다는 것은 이명으로 인 한 심리적인 괴로움이 적을 것이며, 이명의 규모가 크다는 것은 반대로 이명으로 인한 심리적 괴로움이 크게 될 것이라는 것이 다. Hwang and Bahng(2018)은 TMI를 번역하고 신뢰도와 타 당도를 검증하였으며 Lee et al.(2019)은 TMI와 이명도에서의 이명강도와 상관이 없음을 밝혔다. 또한 보청기 착용 전후의 이 명의 변화에 대하여 TMI를 이용하여 효과적으로 측정할 수 있
는 것으로 나타났다(Ha \& Bahng, 2018)

본 연구의 목적은 다음과 같다. 이명을 호소하고 있는 사람들 을 대상으로 간단한 문항으로 구성된 TMI 설문지가 이명이 있 는 사람의 우울 및 불안 등의 감정과 상관관계가 있는지 알아보 고자 한다. 우울 및 불안의 정도를 측정하기 위해서 각각 Beck Depression Inventory 2판(Beck et al., 1996)을 번역하여 한국형으로 개발한 설문지(Sung et al., 2008)와 State Trait Anxiety Inventory (STAI; Spielberger, 1983)를 번역한 한국 판 K-STAI (1996)을 이용하였다.

\section{MATERIALS AND METHODS}

\section{연구 대상}

본 연구는 2019년 2월 15일부터 2019년 11월까지 대전과 충 청남도 천안시에 소재하고 있는 이비인후과에 방문한 환자 중 65명(여성 30명, 남성 35명)을 대상으로 실시하였다. 대상자의 평균 나이는 $56.00 \pm 16.20$ 세였으며, 설문에 참여한 대상자는 주관적 이명을 감지하고 있으나 보청기를 착용하지 않고 청력손 실의 심각성을 느끼지 않고 있었다. 이명을 감지한 기간은 평균 $46.60 \pm 68.58$ 개월이었으며 이명의 종류는 순음과 같은 “비”소 리가 31명이었고 나머지는 매미 소리, 비행기 소리, 개구리 우는 소리, 붕 소리 등 다양한 이명의 소리가 난다고 보고하였다. 이 중 4 명은 설문지 표기를 완성하지 않아 분석에세 제외하였다.

\section{연구 절차}

이명을 주 호소할 경우 연구에 대한 설명한 후 동의서를 받았 다. 연구에 참여하겠다고 한 사람들을 대상으로 다음의 설문지 를 직접 작성하게 하였다. 문항이 이해되지 않는 경우 연구자가 문항에 대하여 간단하게 설명하는 정도였고 최대한 스스로 문제 를 읽고 판단하여 설문에 답하도록 하였다.

\section{연구 도구}

\section{이명규모 설문지}

TMI의 원문은 Schmidt et al.(2014)이 개발하였고 Hwang and Bahng(2018)이 한국어로 번안하였다. 본 연구에서는 한국 어 번안을 마친 설문지를 이용하였다. 설문지는 3 개의 문항이며 이명에 대한 주관적 크기를 묻는 질문이다. 이명규모에 대한 3 가 지 질문항목은 다음과 같다: 1) 지난 한 주 동안 이명은 얼마나 크게 들렸습니까?, 2) 지난 한 주 동안 깨어있는 시간 중에 이명 을 인지한 시간은 몇 \% 정도입니까?, 3) 지난 한 주 동안 이명이 얼마나 심각하게 느껴졌습니까?

원문에서 사용한 척도를 동일하게 사용하였다. 1)과 2) 항 
목은 10점 척도를 사용하였고 3)번 항목은 연속척도를 사용 하였다. 3)번의 연속척도는 $10 \mathrm{~cm}$ 바에 대상자가 느끼는 심 각성을 체크하게 하였고 분석 시 이를 자로 재어 사용하였다 (Appendix 1).

\section{우울척도 설문지}

Beck 우울척도는 Beck et al.(1961)이 개발한 이래 현재까지 전 세계적으로 널리 사용되고 있는 우울증 검사이다. 이 검사는 우울증을 측정하기 위해 개발된 자기보고식 검사로 분위기, 염 세사상, 실패감, 불만족감, 죄악감, 수벌감, 자기혐오, 자기비난, 자기원망, 울고 싶은 기분, 초조감, 사회적 퇴각, 미결정, 신체상, 일의 억제, 수면장애, 피곤, 무식욕, 체중 감소, 신체에의 선입감, 리비도의 결여 항목의 총 21 개의 문항으로 구성되어 있다(Sung et al., 2008). 자기의 기분을 잘 기술하는 정도에 따라 1 번이 0점, 2번이 1점, 3번이 2점, 4번이 3점으로 채점하며, 각 문항 점 수를 합산하여 총점을 구하며, 총점 범위는 0 63점까지로 점수 가 높을수록 우울 정도가 심하고 다양한 우울증상을 보이는 것 으로 해석한다. 0 13점은 약한 우울감, 14 19점 경도의 우울 감, 20 28점은 중도의 우울감 그리고 29점 이상은 심도의 우울 감이 있는 것으로 구분 지을 수 있다(Beck et al., 1996).

\section{상태불안척도 설문지}

STAI검사는 Spielberger(1983)가 개발한 상태불안척도로 언 제나 느끼고 있는 불안 즉 특성불안과 지금 현재 느끼고 있는 불 안 즉 상태불안의 정도를 측정하는 자기 평가식 척도이다. 특성 불안은 불안을 일으키는 특별한 대상이나 사건과 상황이 없는데 도 지속적으로 불안감을 보이며, 자신의 행동에 대해 확신을 갖 지 못하는 상태이고 상태불안은 불안을 일으키는 특별한 대상이 나 상황, 예견되는 실패 등에 대한 위협으로 자율신경계의 활동 을 고조시키며 긴장과 염려의 느낌을 지속적으로 지각하게 하는 것이다. 특성불안척도는 임상 실제에 있어서 신경증적 불안 문제 를 겪고 있는 사람들을 대상으로 환자 집단과 정상 집단을 구분 하기 위한 도구로 사용될 수 있으며, 연구에 있어서는 불안 경향 이 서로 다른 피험자들을 포집하기 위한 도구로 활용될 수 있다. 상태불안척도는 상담, 심리치료 그리고 행동치료 등에서 환자나 내담자가 경험하는 일시적인 불안을 민감하게 포착해 낼 수 있 고, 스트레스, 불안 그리고 학습 등에 관한 실험 연구에서 상태 불안의 변화를 측정하기 위하여 사용된다. 설문문항은 20 문항 씩 총 40문항으로 구성되어 있고, 4점의 리커트식 척도로서, 각 문항마다 '그렇지 않다'는 1점, '가끔 그렇다'는 2점, '자주 그렇 다'는 3점, 거의 '언제나 그렇다'는 4점으로 채점하며, 문항의 성 격에 따라 반대로 채점하는 문항도 있다. 대상자가 얻을 수 있는 점수는 범위는 상태불안 및 특성불안에서 각 20 80점까지이며,
점수가 높을수록 불안 수준이 높은 것을 의미한다. 연구에 따라 조금씩 점수의 기준은 다르지만 한국어판으로 대학생을 대상으 로 한 연구에 따르면 52 56점은 상태불안 수준이 약간 높은 정 도, 57 61점은 상태불안 수준이 상당히 높은 정도, 62점 이상은 상태불안 수준이 매우 높음 정도라고 할 수 있다(Kim, 1978).

\section{통계 분석}

SPSS version 25.0 (IBM Corp., Armork, NY, USA)을 사 용하여 TMI와 우울척도와 상태불안척도의 상관관계를 분석하 였다. 분석은 각 설문지를 기술통계로 분석하였으며, 각 설문지 간의 상관관계는 비모수 상관관계 분석인 Spearman's rankorder correlation을 사용하였으며 유의수준 0.05 로 분석하였다.

\section{RESULTS}

본 연구에서는 실시한 3 개의 설문지의 결과를 분석하고 TMI 와 우울, 불안척도와의 상관관계를 측정하기 위하여 우울척도 (Korean version of Beck Depression Inventory II, K-BDI $\mathrm{II})$ 와 상태불안척도 설문지(K-STAI)를 비모수 검정 상관관계로 분석하였다.

\section{이명규모 설문 결과}

61명의 대상자의 데이터 값의 결과는 다음과 같다. 세 문항 모 두 10점 척도로 변환하여 분석하였다. TMI의 첫 번째 문항의 답 변의 평균값은 $4.39 \pm 2.19$ 였다. TMI의 두 번째 문항의 평균은 $3.07 \pm 2.45$ 였으며, TMI의 마지막 문항의 평균은 $2.45 \pm 2.81$ 이었다(Table 1). TMI의 척도는 10점 척도임으로 본 연구의 참 여한 대상자들은 중간 정도의 이명의 규모를 가진 것으로 해석 할 수 있다.

\section{우울척도와 상태불안척도 설문 결과}

61명의 대상자의 우울척도와 상태불안척도의 결과는 다음과

Table 1. Mean (SD), minimum and maximum scores for TMI

\begin{tabular}{llcc}
\hline & Mean (SD) & Minimum & Maximum \\
\hline TMI & & & \\
TMI 1 & $4.39(2.19)$ & 0 & 9 \\
TMI 2 & $3.07(20.45)$ & 0 & 10 \\
TMI 3 & $2.45(2.81)$ & 0 & 10 \\
K-BDI II & $8.75(6.15)$ & 0 & 24 \\
K-STAI & $40.40(9.39)$ & 20 & 61 \\
\hline
\end{tabular}

SD: standard deviation, TMI: Tinnitus Magnitude Index, K-BDI II: Korean version of Beck Depression Inventory II, K-STAI: Korean version of State Trait Anxiety Inventory 
같다. 우울척도의 평균값은 $8.75 \pm 6.15$ 였다. 상태불안척도의 평균값은 $40.4 \pm 9.39$ 였다(Table 1). 두 설문지 모두 점수가 높 을수록 우울과 불안의 정도가 큰 값을 의미한다.

Lim et al.(2011)은 우울 집단을 선별하기 위한 절단점을 한 국판 연구에서는 우울 집단의 선별을 위한 절단점으로 18 점을 제시하였다. 본 연구에서 24점 이상을 보인 대상자는 6명이었다. 상태불안척도에서는 $\operatorname{Kim}(1978)$ 의 연구 결과에 따라 상태불안 척도가 약간 높은 52점 이상 또한 앞의 우울척도와 같은 6명이 었다. 이 설문지에서 모두 불안과 상태불안척도가 높은 대상자 는 4 명이었다.

\section{이명규모와 우울척도, 상태불안척도와의 상관관계}

이명과 우울, 불안척도와의 관계를 살펴보기 위하여 비모수 이변량 상관관계 분석인 Spearman의 rho를 실시한 결과 TMI 의 각각의 문항과 $\mathrm{K}-\mathrm{BDI} \mathrm{II}, \mathrm{K}-\mathrm{STAI}$ 와는 상관관계가 없는 것 으로 나타났다. 반면 우울척도와 상태불안척도와의 상관관계는 0.7 ( $p<0.05)$ 을 나타내어 중간 이상의 상관관계를 나타내는 것 으로 나타났다(Figure 1).

$\mathrm{TMI}$ 의 각 문항은 서로 간의 상관관계는 1 번과 2번 문항은 0.611 ( $p<0.05), 1$ 번과 3번 문항은 0.533 ( $p<0.05), 2$ 번과 3번 문항은 $0.512(p<0.05)$ 로 중간 정도의 상관관계를 가지고 있는 것으로 나타났다(Table 2). 즉, 이명을 크게 느끼는 사람들이 이 명을 오랜 시간 인지하고 있었으며, 또 심각하게 느끼고 있다는 뜻으로 해석할 수 있다.

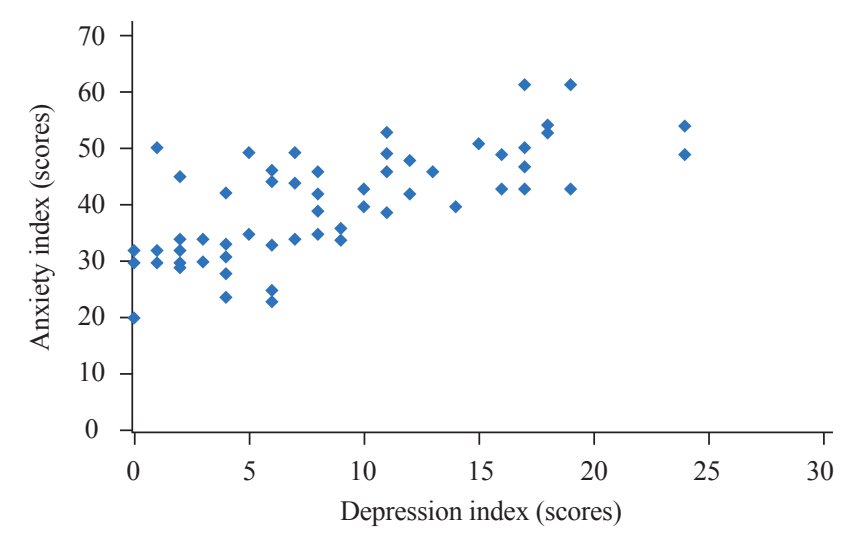

Figure 1. Scatter plot of depression and anxiety indexes.

Table 2. The correlation coefficient among items of TMI

\begin{tabular}{lcll}
\hline & TMI 1 & TMI 2 & TMI 3 \\
\hline TMI 1 & 1.000 & $0.611^{\star *}$ & $0.533^{\star *}$ \\
TMI 2 & - & 1.000 & $0.512^{\star *}$ \\
TMI 3 & - & - & 1.000 \\
\hline
\end{tabular}

${ }^{* *} p<0.01$. TMI: Tinnitus Magnitude Index

\section{우울 정도와 상태불안이 심한 대상자와 이명규모 비교}

Lim et al.(2011)의 연구에 따르면 BDI II를 사용할 경우 우울 집단 선별 시 절단점을 18 점으로 할 때 높은 민감도와 특이도를 나타내었다. BDI-II의 절단점에 관한 연구는 연구 대상에 따라 다르기 때문에 이를 고려하여야 하지만 본 연구에서는 Lim et al.(2011)에서 제시한 18점을 절단점으로 하여 분석하였다.

상태불안척도(Kim, 1978)에서는 대학생을 대상으로 검사한 결과 52점 이상을 상태불안 수준이 약간 높음, 57 61점은 상태 불안 수준이 상당히 높음, 52점 이상을 상태불안 수준이 매우 높음이라고 보고하였다. 본 연구에서도 52점 이상을 상태불안 수준이 높다고 판단하고 분석하였다.

연구에 참여한 대상자 중 K-BDI II 18점 이상을 나타내고 30점 이상의 K-STAI를 보인 대상자 23명을 대상으로 두 설문지와 $\mathrm{TMI}$ 와의 상관관계를 살펴보았다. $\mathrm{BDI}$ 의 설문지 6번인 "나는 벌 을 받고 있다"(rho = -0.574, $p<0.05)$ 와 TMI 3번 문항, BDI 9번 문항 “나는 자살할 것 같다”와 TMI 3번 문항(rho $=-0.791$, $p<0.05)$, BDI 15 번 문항 “나는 전처럼 일할 수 있다”와 TMI 1 번 문항에서 유의한 관계(rho = -0.693, $p<0.05)$ 를 나타내었다.

\section{DISCUSSIONS}

본 연구의 목적은 한국어판 TMI 설문지를 이용하여 이명을 느끼나 심각한 청력손실을 보고하지 않은 자들의 불안과 우울과 의 상관관계를 분석하여 TMI가 이러한 이명을 겪고 있는 대상 자의 심리적 상태를 반영하는지 검증하고자 하였다.

많은 선행 연구에서 이명과 불안, 우울에 대한 관계는 유의 한 상관관계가 있다고 밝혔다(Kim et al., 2015; Trevis et al., 2016). 선행 연구의 결과 이명과 우울, 상태불안과 같은 심리 적 불안은 이명에 대한 심각성이 커질수록 심각해 질 수 있다고 하였다(Trevis et al., 2016). 또한 이러한 심리적 불안은 이명 의 심각성에 대한 예측을 할 수 있다고 하였다(Strumila et al., 2017).

본 연구에서는 앞의 선행 연구와 같은 결과를 반영하지 못하 였다. 그 이유에 대한 가능성을 분석한 결과는 다음과 같다. 첫 째, 이명의 심리적 강도와 심각성 그리고 이명의 지속시간 등은 우울, 불안상태와 연관성이 크지 않다. 선행 연구에서는 이명으 로 인한 부정적인 어려움은 개인의 청각, 의학, 심리적 특성에 따 라 다양하게 나타나며 이러한 차이를 만들어 내는 것은 이명의 강도라고 하였다(McCombe et al., 2001; Tyler \& ConradArmes, 1983; Tyler et al., 1989). TMI 개발자인 Schmidt et al.(2014)은 이명의 지각(perception)이 이명으로 인한 심리 적 고통반응(reaction)과 관련이 있다고 하였다. 이명강도와 고 통반응의 인과관계에서 기능적 간섭과 자기 조절의 요소는 이 
명으로 인한 고통반응, 즉 심리적 인지강도에 영향을 줄 수 있다 고 하였다. 본 연구에서는 우울과 불안상태가 심한 대상자를 분 류하여 분석한 결과 TMI와 우울과 불안을 묻는 설문지의 일부 문항만이 중간 정도의 상관관계를 나타내었다. 본 연구의 결과 Schmidt et al.(2014)의 이론으로 개발된 TMI가 우울과 불안 의 요소를 민감하게 반영하지는 못하고 일부만 반영하는 것으로 나타났다.

둘째, 본 연구에 참여했던 대상자들의 특성에서 찾을 수 있다. 본 연구에 참여했던 대상자들은 이명을 주 호소로 내원하였으나 심각한 청력손실을 보고하지 않아 보청기 등의 보장구를 사용하 지 않는 대상자였다. Jeong et al.(1997)에 따르면 이명은 있으 나 청력손실이 없는 경우 청력손실과 함께 이명이 있는 사람보다 우울, 상태불안의 정도가 덜하다고 보고하였다. 본 연구에 참여 했던 대상자 모두 보청기, 인공와우 등의 보장구를 착용하지 않 은 스스로를 정상청력으로 간주한 대상자였다. 본 연구의 결과가 Jeong et al.(1997)의 연구 결과에서와 마찬가지로 TMI와 우울, 불안척도와 상관관계가 없는 것으로 나타났을 가능성이 있다. 또한 TMI의 문항에서의 답변도 중간 정도의 이명의 자각을 나 타내는 것을 볼 수 있어 상관관계가 나타나지 않는 이유로 분석 할 수 있다. 또한 우울척도의 분포도를 보면 대부분의 정상군인 10 점 이하를 나타내고 있다. 참여 대상자의 대부분이 '우울하지 않은 카테고리에 속하여 상관관계를 정확히 분석할 수 없었다고 볼 수 있다. 상태불안척도에서도 많은 수의 대상자가 '상태가 불 안하지 않은 카테고리에 속하여 TMI와의 상관관계가 분명히 나 타나지 않았을 수 있다고 분석하였다. 청력손실 여부를 확인하지 못한 점과 많은 이명인들이 본 연구에 참여하지 못한 점은 이 연 구의 제한점이라 할 수 있다.

본 연구의 결과는 비록 TMI가 우울과 상태불안척도의 상관 관계가 나타나지 않았지만 TMI 간의 상관관계가 높으며 우울 과 상태불안과는 높은 상관관계를 갖는 것으로 나타났다. 즉, 비록 TMI 설문문항들이 우울과 상태불안과 같은 심리적인 문 제에 대하여 민감하지 않았지만 항목 간의 상관관계가 높아 심 리적인 크기를 크게 느끼는 경우 이명에 대한 심각성을 심각하 게 느끼며 인지하고 있는 시간이 긴 것으로 나타났다. 선행 연 구에 따르면 보청기 사용 전과 후에 TMI를 이용하였을 때 보청 기 착용 후 $\mathrm{TMI}$ 의 점수가 유의하게 나타난 것으로 보고하였다 (Ha \& Bahng, 2018). 또한 TMI와 임상에서 많이 쓰이는 THI (Newman et al., 1996), THQ (Kuk et al., 1990)와 중간관계 의 상관관계를 나타나는 것으로 보여(Lee et al., 2019), TMI의 경우 이명을 느끼는 정도에 대한 선별검사의 목적으로 사용할 때 유용할 것으로 본다. 또한 이명에 대한 설문으로 집단적으로 분석하는 것보다 개개인의 변화를 측정하는 데 TMI 설문지를 유용하게 사용할 수 있을 것이다. 예를 들어 이명의 재활 전 측정
한 TMI의 문항 1 번이 7점이었다고 할 때 재활 후 측정한 결과가 3점으로 된 경우 이명이 들리는 주관적 크기가 줄어들었다고 해 석할 수 있다. 다른 문항 또한 이명의 재활 전후를 비교하여 이명 이 들리는 사람들의 재활의 효과를 측정하는 데 이용할 수 있을 것이다.

본 연구의 결과로 TMI는 이명으로 인한 심리적 문제를 민감 하게 반영하지는 못하는 것으로 나타났지만 불안과 우울은 함께 발생할 가능성이 높다는 것을 파악할 수 있었다. 이명으로 인한 심리적인 문제를 파악하기 위해서는 좀 더 우울과 불안의 상태 를 파악할 수 있는 설문지를 사용하고 이명 재활 전과 후에 이에 대한 문제가 해결이 되었는지 확인해야 할 것이다.

중심 단어 : 이명, 이명규모 설문지, 우울, 불안.

\section{Ethical Statement}

This study was approved by the Institutional Review Board of Hallym University of Graduate Studies (HUGSAUD \#507824).

\section{Acknowledgments \\ N/A}

\section{Declaration of Conflicting Interests}

Junghwa Bahng, a contributing editor of the Audiology and Speech Research, was not involved in the editorial evaluation or decision to publish this article. All remaining authors have declared no conflicts of interest.

\section{Funding \\ N/A}

\section{Author Contributions}

Conceptualization: Ha Ryun Kim, Junghwa Bahng. Data collection: Ha Ryun Kim. Formal analysis: Ha Ryun Kim, Junghwa Bahng. Methodology: Ha Ryun Kim. Writing-original draft: Ha Ryun Kim. Writing-review \& editing: Junghwa Bahng. Approval of final manuscript: Junghwa Bahng.

\section{ORCID ID}

Ha Ryun Kim https://orcid.org/0000-0001-7387-3556

Junghwa Bahng 


\section{REFERENCES}

American Tinnitus Association (ATA). (2019, October 29). Understanding the Facts. ATA. Retrieved from https://www.ata. org/understanding-facts.

Bahng, J. \& Lee, C. H. (2020). Topic modeling for analyzing patients' perceptions and concerns of hearing loss on social Q\&A sites: Incorporating patients' perspective. International Journal of Environmental Research and Public Health, 17(17), 6209.

Beck, A. T., Steer, R. A., Brown, G. K. (1996). Manual for the Beck Depression Inventory-II. (2nd ed.), (pp.1-82). San Antonio, TX: Psychological Cooperation.

Beck, A. T., Ward, C. H., Mendelson, M., Mock, J., \& Erbaugh, J. (1961). An inventory for measuring depression. Archives of General Psychiatry, 4, 561-571.

Dauman, R. \& Tyler, R. S. (1992). Some considerations on the classification of tinnitus. In Aran, J. M. \& Dauman, R. Tinnitus 91: Proceedings of the Fourth International Tinnitus Seminar (pp.225229). Amsterdam: Kugler Publications.

Ha, Y. R. \& Bahng, J. (2018). The effectiveness of hearing aids on tinnitus management for hearing-impaired listeners with tinnitus. Audiology and Speech Research, 14(4), 243-249.

Han, B. I., Lee, H. W., Kim, T. Y., Lim, J. S., \& Shin, K. S. (2009). Tinnitus: Characteristics, causes, mechanisms, and treatments. Journal of Clinical Neurology, 5(1), 11-19.

Hwang, D. H. \& Bahng, J. (2018). A Korean adaptation of the tinnitus magnitude index: Validity and reliability. Audiology and Speech Research, 14(2), 90-99.

Jeong, S. H., Kang, S. H., Lee, Z. N., Kang, B. J., \& Rim, H. D. (1997). Review of psychiatric approaches to tinnitus. Journal of the Korean Society of Biological Therapies in Psychiatry, 3, 250-257.

Kim, H. J., Lee, H. J., An, S. Y., Sim, S., Park, B., Kim, S. W., et al. (2015). Analysis of the prevalence and associated risk factors of tinnitus in adults. PLoS One, 10(5), e0127578.

Kim, J. T. (1978). The relation between trait anxiety and social abilities: Focusing on Spielberger's STAI (Unpublished master's thesis). Seoul: Korea University.

Kraus, K. S. \& Canlon, B. (2012). Neuronal connectivity and interactions between the auditory and limbic systems. Effects of noise and tinnitus. Hearing Research, 288(1-2), 34-46.

Kuk, F. K., Tyler, R. S., Russell, D., \& Jordan, H. (1990). The psychometric properties of a tinnitus handicap questionnaire. Ear and Hearing, 11(6), 434-445.

Lee, J., Lee, K., Oh, H., Jeong, S., \& Jin, I. K. (2018). Analytical review of tinnitus questionnaires: Characteristics and understanding. Audiology and Speech Research, 14(2), 73-80.

Lee, K. E., Oh, S. H., \& Bahng, J. (2019). Clinical implication of tinnitus magnitude index. Audiology and Speech Research, 15(3), 176-183.

Lim, S. Y., Lee, E. J., Jeong, S. W., Kim, H. C., Jeong, C. H., Jeon, T. Y., et al. (2011). The validation study of Beck Depression Scale 2 in Korean version. Anxiety and Mood, 7(1), 48-53.

Makar, S. K., Biswas, A., \& Shatapathy, P. (2014). The impact of tinnitus on sufferers in Indian population. Indian Journal of Otolaryngology and Head and Neck Surgery, 66(Suppl 1), 37-51.

McCombe, A., Baguley, D., Coles, R., McKenna, L., McKinney, C., Windle-Taylor, P., et al. (2001). Guidelines for the grading of tinnitus severity: The results of a working group commissioned by the British Association of Otolaryngologists, Head and Neck Surgeons, 1999. Clinical Otolaryngology and Allied Sciences, 26(5), 388-393.

Michikawa, T., Nishiwaki, Y., Kikuchi, Y., Saito, H., Mizutari, K., Okamoto, M., et al. (2010). Prevalence and factors associated with tinnitus: A community-based study of Japanese elders. Journal of Epidemiology, 20(4), 271-276.

Moring, J., Bowen, A., Thomas, J., \& Bira, L. (2016). The emotional and functional impact of the type of tinnitus sensation. Journal of Clinical Psychology in Medical Settings, 23(3), 310-318.

Newman, C. W., Jacobson, G. P., \& Spitzer, J. B. (1996). Development of the tinnitus handicap inventory. Archives of Otolaryngology--Head and Neck Surgery, 122(2), 143-148.

Oiticica, J. \& Bittar, R. S. (2015). Tinnitus prevalence in the city of São Paulo. Brazilian Journal of Otorhinolaryngology, 81(2), 167-176.

Schmidt, C. J., Kerns, R. D., Griest, S., Theodoroff, S. M., Pietrzak, R. H., \& Henry, J. A. (2014). Toward development of a tinnitus magnitude index. Ear and Hearing, 35(4), 476-484.

Spielberger, C. D. (1983). Manual for the State-Trait Anxiety Inventory: STAI (form Y). Palo Alto, CA: Consulting Psychologists Press.

Strumila, R., Lengvenytė, A., Vainutiene, V., \& Lesinskas, E. (2017). The role of questioning environment, personality traits, depressive and anxiety symptoms in tinnitus severity perception. The Psychiatric Quarterly, 88(4), 865-877.

Sung, H. M., Kim, J. B., Park, Y. N., Bai, D. S., Lee, S. H., \& Ahn, H. N. (2008). A study on the reliability and the validity of Korean version of the Beck Depression Inventory-II (BDI-II). Journal of the Korean Society of Biological Therapies in Psychiatry, 14(2), 201-212.

Trevis, K. J., McLachlan, N. M., \& Wilson, S. J. (2016). Psychological mediators of chronic tinnitus: The critical role of depression. Journal of Affective Disorders, 204, 234-240.

Tyler, R. S. \& Conrad-Armes, D. (1983). The determination of tinnitus loudness considering the effects of recruitment. Journal of Speech and Hearing Research, 26(1), 59-72.

Tyler, R. S., Stouffer, J. L., \& Schum, R. (1989). Audiological rehabilitation of the tinnitus client. Journal of the Academy of Rehabilitative Audiology, 22, 30-42. 


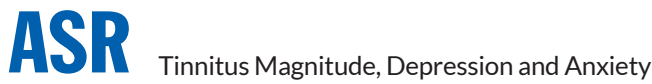

\section{APPENDIX}

Appendix 1. Korean version of Tinnitus Magnitude Index

1) 지난 한 주 동안 이명이 얼마나 크게 들렸습니까?

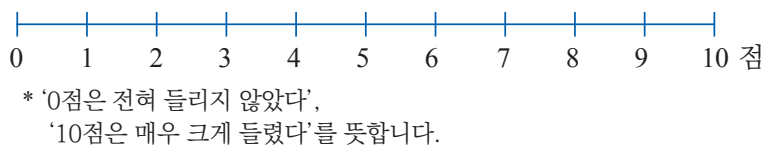

2) 지난 한 주 동안 깨어 있는 시간 중 이명을 인지한 시간은 몇 \% 정도 입니까?

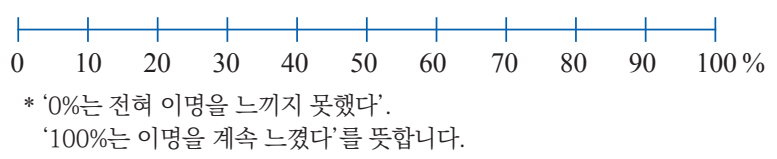

3) 지난 한 주 동안 이명이 얼마나 심각하게 느껴졌습니까?

전혀 심각하지 않다.

매우 심각하다.

* 위의 막대에 이명의 심각 정도를 느끼는 바를 표시하세요.

왼쪽으로 갈수록 이명이 심각하지 않음을, 오른쪽은 이명의 심각이 심해짐을

뜻합니다. 